
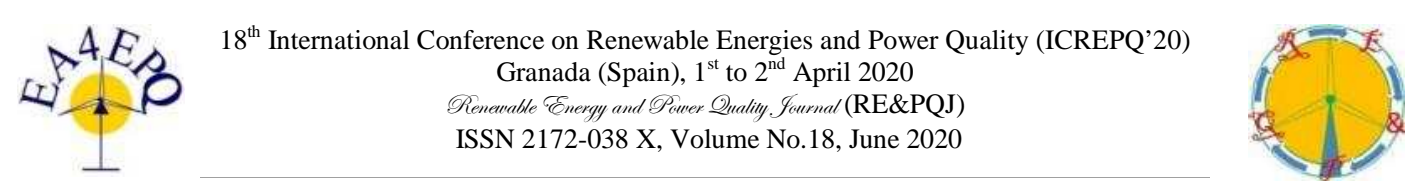

\title{
Optimal location decision of wind generators in urban areas using multi criteria techniques.
}

\author{
E. Morocho ${ }^{1}$, W. Morocho ${ }^{1}$, A. Barragán ${ }^{1}$ and E. Zalamea ${ }^{4}$ \\ ${ }^{1}$ Carrera de Ingeniería Eléctrica, Universidad Politécnica Salesiana \\ Sede Cuenca - Calle Vieja 12-30 y Elia Liut, Cuenca (Ecuador), Phone: (583) 07- 413-5250, \\ e-mail: emorochod@est.ups.edu.ec,wmorochoc@est.ups.edu.ec, ebarragan@ups.edu.ec \\ ${ }^{4}$ Facultad de Arquitectura y Urbanismo, Universidad de Cuenca \\ Av. 12 de Abril y Av. Loja, Cuenca (Ecuador), Phone: (593) 0983311604 \\ e-mail: esteban.zalamea@ucuenca.edu.ec
}

\begin{abstract}
The inclusion of urban energy self-supply alternatives is an optimal condition to face the growth trend in energy infrastructures and nature impact as its consequence. Powering the urban grid including wind turbines inner the urban boundaries In Cuenca, Ecuador as case study have been analysed in this research. This city and its surroundings possess an average annual wind speed of 4 to $5 \mathrm{~m} / \mathrm{s}$, depending on different spots conditions, altitude and site characteristics. The PROMETHEE method is used to figure out the best suitable area to take advantage of the wind source for electric power in ranges less than 10KW (micro-scale). Four sites are determined as suitable alternatives, and they are evaluated based on sets of technical, economic, environmental and social criteria. For a more reliable solution, we propose three different scenarios based on different weighting methods. As consequence, the Turi location turns out to be the best option because geographical and wind conditions at the zone. However, it is necessary to analyze aspects related to visual and environmental impact for an adequate implementation of this type of projects.
\end{abstract}

Keywords: Micro-generation, Urban wind power, MCDA, Promethee, Visual Promethee.

\section{Introduction}

Research on integration of Renewable Energy (RE) encourage the use of accessible, affordable and clean own and proper resources. The adoption and implementation of ERs on Urban Environments (UE) has attracted attention because more than promoting clean and inexpensive energy, covering the growing energy consumption. As urban environments exist concentration of residential buildings, industrial areas, densely populated areas, large number of dwellings and diverse infrastructure with a high population density. Continuous improvements in development of ERs integrated on UEs are: solar thermal, photovoltaic and biomass. However, there is growing interest in wind urban integration as well [1-3].

Wind power is a promising alternative as sustainable resource and environmentally friendly. Besides this technology is a proper alternative as complementary with other clean intermittent sources such as photovoltaic, solar thermal or hydropower. This technology can be complementary to the provision of energy, as well as an option to diversify production when other sources are minimal or non-existent [4]. This has led to technological advances in the design of micro turbines that can be integrated into the urban landscape. In urban areas there are different (alternative) sites where the power of the wind can be harnessed. However, for these alternatives to be adequate, conditions must be met that depend not only on the characteristics of the wind, but also on the urban configuration.

Between several alternatives, it is necessary to determine which corresponds better to the environmental and social aspects, not only from a technical perspective. So, there is a decision concern. In order to assist in this decision process, it has been developed a set of methods for multicriteria decision analysis (MCDA). These methods allow to consider quantitative, qualitative data or a mixture of the two. The use of techniques of multicriteria on issues of energy studies is an alternative to evaluate different dimensions (social, environmental, economic or technical) about wind integration on urban environments.

\section{Wind characteristics in urban environments}

Wind potential in a UE depends on the topography, buildings size and geometry, air density or the temperature of the place [5]. Wind potential in UEs could be quite useful, but there have been few studies that focus on assessing the benefits of harnessing this potential in cities [6].

The presence of buildings has a significant effect on wind flows modifying the main characteristics of this resource, then they modify the pressure, speed, direction and turbulence. These factors does influence in the physical characteristics: the surface roughness, the shape of the facades and roofs and the height and size of buildings, the dimension of streets or open areas [5], [7]. 
As the wind flows hits building facades, high and low pressures appear. The low-pressure zones extends on the back side creating an area where the wind is turbulent and inadequate. In (Fig.1), the wind behaviour shown in UE eddies or air waves is observed with non-uniform oscillation. This causes vibration in buildings and impact of moving elements, from the perspective landscape [8].

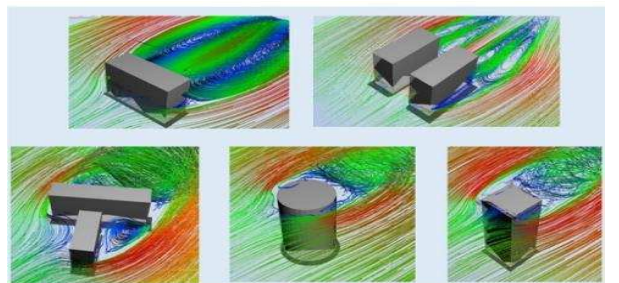

Fig.1. Behaviour wind colliding with different surfaces Source: self-made

\section{Decision multicriteria Methods (MCDA)}

Decision process requires diverse comparisons between different alternatives in order to establish a preference level. The decision is related to a set of views, to which can be defined as criteria [9]. The multicriteria methodologies integrate several factors that are achieved in the evaluation process. The multi criteria methods are useful for criteria evaluation assigning weights (points) accordingly to adopted scales, which are analysed in each alternative comparison [10], [11].

\section{A. Classification methods (outranking)}

Classification methods identify whether alternatives are preferable, incomparable or indifferent on the each adopted criterion. They are useful for diverse alternatives classification, which have many different criteria to each other. Additionally, to find the preferred criteria, it is necessary to determine how much an alternative is favourable on another. In these methods the decider is who expresses full preference or indifference in comparing options [12], [13]. One method commonly used in the energy field is the PROMETHEE method.

\section{B. PROMETHEE method}

It was developed in 1982 by Brans, assesses the strengths and weaknesses of the alternatives [14], [15]. It is based on a pairwise comparison, setting key alternatives. This method is suitable for selection of alternative tracks based on multiple criteria, allowing a direct comparison of alternatives regarding specific criteria [16]. The process followed by the PROMETHEE method, can be seen in Fig. 2 .

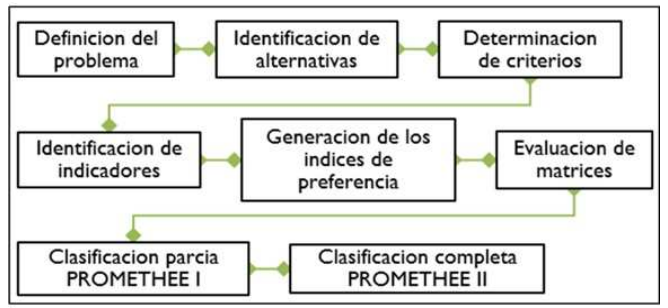

Fig.2. Process method PROMETHEE
Solving a problem with the PROMETHEE method must follow a set of steps: First, the deviation is determined, which refers to the distance of two alternatives within a single criterion. Based on the magnitude of the deviation, the decider assigns a preference. As the same time, it is necessary to establish if the objective is to maximize or minimize the results. Then the index is calculated expressing the degree to which an alternative is preferable from another.

Once the above is established, the preference indices between each two alternatives are calculated. The positive and negative preference flows of each alternative are defined as the sum of the preference indices, respectively, of one alternative towards the others and of the others towards it. The best alternative is the greatest value of all positive flows and the lowest value of negative flow.

Finally, a complete classification is done. The valuation of flows ranking of alternatives from highest to lowest is obtained.

\section{Case study}

PROMETHEE in this study is implemented for determining optimal conditions for the implementation of micro wind generation equipment in the urban area of the city of Cuenca (3665.32 km2). Cuenca is located in the south-central region of the Republic of Ecuador (Fig. 3). Its downtown is located at 2535 meters over the sea level, close to the equatorial line. The urban population is 329,298 inhabitants corresponding to $65.3 \%$ of the total population [30].

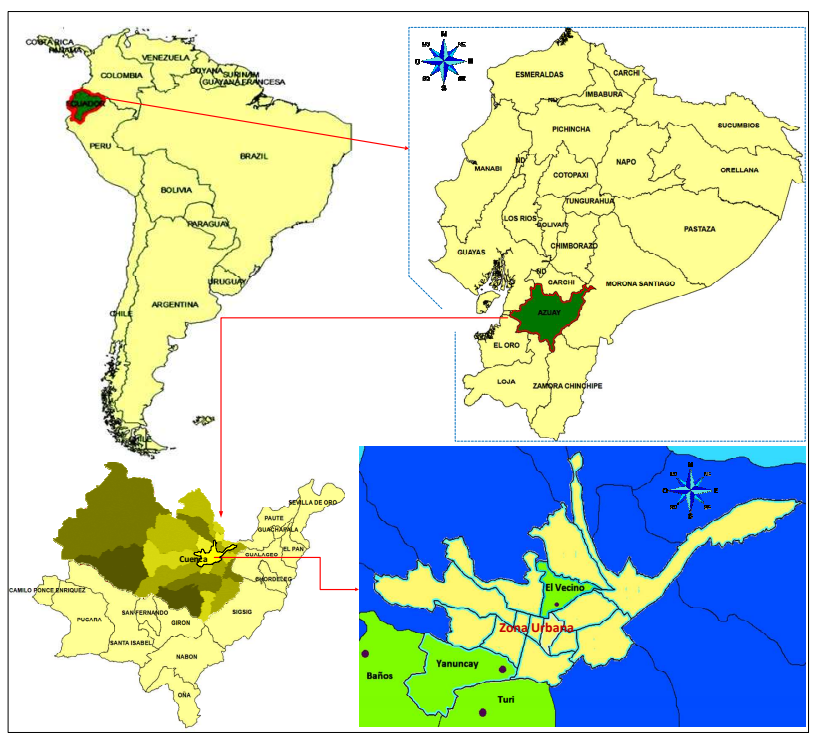

Fig.3. Location of the city of Cuenca-Ecuador

Four places in Cuenca have been considered for this study: Turi, Baños, El Vecino and Yanuncay. Baños, is an urban zone emplaced at the south west of the city $(2580 \mathrm{~m})$; then Turi located south, in a higher zone (2600 $\mathrm{m}$ altitude), Yanuncay located southwest $(2560 \mathrm{~m}$ altitude) and finally El Vecino, a more dense urban area located northeast of the city of Cuenca (2530 m altitude). 
This zones has been characterized because a higher wind presence.

The characteristics of land use and the maximum permitted height for buildings in each location are noted in Table I.

The Table shows characteristics of land use and the heights allowed for buildings.

Table I. - Characteristics of each alternative

\begin{tabular}{|l|c|l|}
\hline ALTERNATIVE & $\begin{array}{c}\text { TYPE OF LAND } \\
\text { USE }\end{array}$ & \multicolumn{1}{c|}{ MAXIMUM } \\
BUILDING HEIGHT
\end{tabular}

\section{Criteria grouping}

Sub-criteria are established based on a literature review. This background allowed a criteria selection. Thus, four sets of criteria are identified: technical, economic, environmental and social.

\section{A. Technical criteria}

These criteria include technical conditions required for wind turbines to generate electricity under optimum conditions.

Turbulence intensity (C1): This condition determines what level of turbulence at a specific site. The turbulence intensity is the ratio between the standard deviation of the wind speed and the average wind speed, [17], [18] (1).

$$
T I=\frac{\sigma^{2}}{\bar{v}}
$$

Wind power available (C2): Determines the availability of wind resources for electricity production. It is necessary to know the behaviour of the wind in a specific zone. This could be calculated using the Weibull distribution [19], [20] (2).

$$
f(v)=\left(\frac{k}{c}\right) *\left(\frac{v}{c}\right)^{k-1} * \lambda^{-\left(\frac{v}{c}\right)^{k}}
$$

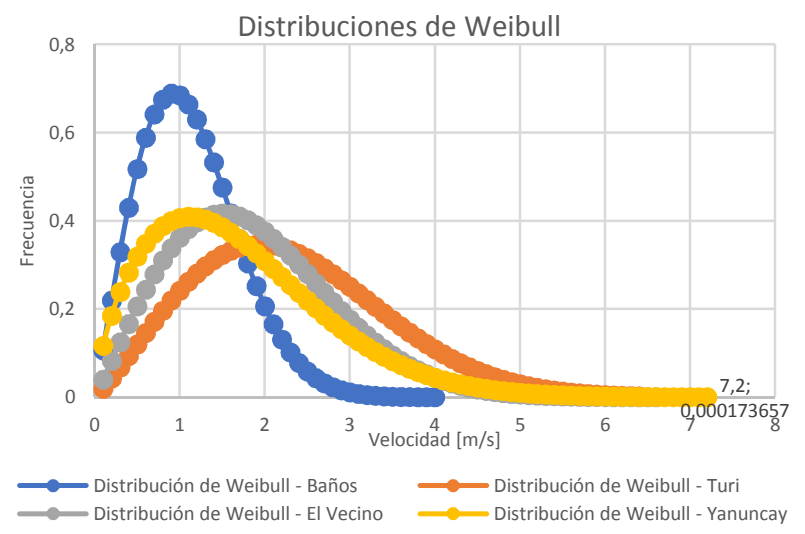

Fig.4. Distribution of Weibull of each study area

In (Fig. 4), wind speed availability in each urban spot is measured. This graph indicates that the Baños location has a closed distribution which means that the speeds are more constant, but its value is low. While the other three locations have distributions that are not so closed, which means a variation between speeds, but with higher values. The wind potential is proportional to the cube of the instantaneous wind speed and wind density. Because of this cubic term, two sites with the same average wind speed, but with different distributions can have very different values of power density. The power density in the wind, in units of $\mathrm{W} / \mathrm{m}^{2}$. It is described using Equation (3).

$$
P / A=\frac{1}{2} \rho v^{3}
$$

Maximum permitted height for buildings (C3): Sets the height of harnessing the wind. These data are obtained from the municipal land where the maximum height of construction of buildings [5] is specified. The characteristics of each alternative are seen in Table I, also the type of land use.

\section{B. Economic criteria}

These criteria could be measured based on estimated prices and economic benefits of the technology implementation.

Annual financial savings (C4): Is the annual energy cost savings by implementing wind generation equipment. This indicator does not take into account investments for the purchase of power generation equipment and other additional costs [19], [20]. Currently, the commercial price per $\mathrm{kWh}$ is 0.095 USD (according to the tariff schedule of Ecuador) [21].

Economic benefit (C5): establishes the economic results by implementing wind generation. The criteria will vary based on the type of land costs, it is assumed that there is greater benefit in tourism industry that residential or industrial [19] place [20].

\section{Environmental criteria}

This set of criteria is based on the effects on local wildlife or visual impact caused by the implementation of the technology. Changes and impact in animal behaviour must be detected (C6) evaluating the alterations induced to wildlife [22].

Also, visual impact (C7) reflects the aesthetic alteration to the UE. So, it is necessary to detect implications to the urban landscape [22].

Complementary to wild life, particularly it must be taken account the collision risk of birds with turbines (C8), this aspect should be associated also [23]. 


\section{Social criteria}

There are related aspects of human and social consequences. These criteria demonstrate the expectations and affections that society has when implementing a new power generation system, especially when these are near to residential sites.

Availability area (C9): Defines if there are open space where a wind turbine can be implanted. The available areas are reduced in urban environments because most of the open space are close or on the buildings. Integration into buildings has visual implications, vibration, noise and unwanted and distracting motion [23], [24].

Social acceptance (C10): Considers whether the citizens would do accept to incorporate wind turbines near homes or workplaces to meet their energy consumption, contributing to reduce impacts to natural external environments [24].

\section{Indicators for each sub-criterion}

Table II. - Complete list of indicators for each sub-criteria analysis

\begin{tabular}{|l|c|r|r|r|r|}
\hline \multicolumn{7}{|c|}{ CRITERIA and SUB-CRITERIA } \\
\hline CRITERIA & & Baños & Turi & $\begin{array}{c}\text { El } \\
\text { Vecino }\end{array}$ & Yanuncay \\
\hline \multirow{5}{*}{ Technical } & $\mathrm{C} 1$ & 0.42 & 0.50 & 0.58 & 0.64 \\
\cline { 2 - 7 } & $\mathrm{C} 2$ & 259.192 & 1963.78 & 1205.73 & 1959.06 \\
\cline { 2 - 7 } & $\mathrm{C} 3$ & 2 & 2 & 6 & 9 \\
\hline Economic & $\mathrm{C} 4$ & 163.66 & 1000.36 & 641.36 & 572.34 \\
\cline { 2 - 7 } & $\mathrm{C} 5$ & 2.25 & 2.33 & 2.00 & 2.00 \\
\hline Environmental & $\mathrm{C} 6$ & 2.33 & 2.42 & 1.92 & 2.25 \\
\cline { 2 - 6 } & $\mathrm{C} 7$ & 2.50 & 2.92 & 2.92 & 2.92 \\
\cline { 2 - 6 } & $\mathrm{C} 8$ & 3.00 & 3.00 & 2.08 & 2.42 \\
\hline \multirow{5}{*}{ Social } & $\mathrm{C} 9$ & 2.92 & 3.50 & 2.67 & 3.00 \\
\cline { 2 - 6 } & $\mathrm{C} 10$ & 3.50 & 3.42 & 2.75 & 2.83 \\
\hline
\end{tabular}

The sub-criteria should be evaluated by quantitative or qualitative indicators. Quantitative indicators are determined by calculations from the technical or geometrical properties of wind turbines characteristics as well as the marketing costs.

Qualitative indicators consider environmental and social criteria and are obtained by evaluation of professionals with high knowledge about the subject. The questionnaire was designed with closed questions to determine the indicators comparisons. The survey questions were formulated to be answered on a numerical Likert scale of $1-5$.

Table II indicators for each sub-criterion is applicable areas. Also, it indicates whether the sub-criterion should be maximized or minimized.

\section{Weight or value of importance of each sub-criteria}

The value of each sub-criteria indicates the level of preponderance compared with another one [25]. There are different methods for selecting preponderance weights:

\section{A. Subjective evaluation methods}

In this case the weights or value must be set by the decider. The values obtained will result from the preference and judgment of the decision maker [25].

\section{B. Methods objective weighting}

This method is based on the use of algorithms or mathematical models in order to determine the value of the weights. It is independent of the particular preferences of decision makers [25].

\section{Scenarios}

Three scenarios are analysed, each with a different weighting method.

First scenario: the "Equal weight allocation" was used. The method is based on placing a weight of the same value to each criterion set by the decider. Second scenario: subjective method of "Points allocation" was used. Obtaining these weights for each sub-criterion it is done through surveys with professional's participation. In these surveys a value on a scale from 1 to 10 is performed, in order the measure the importance of a criterion against others based on the knowledge and experience of each professional. Third stage: the goal of " Critic weighting method " method is used. Method proposed by Diakoulaki in 1995, in which it performs a correlation between the values defining the importance of each criterion in order to obtain a value accordingly [26].

The weights obtained for each scenario are shown in Table III. These values define the final level of importance given to each sub in different scenarios.

For Scenario 1, it shows that all weights are equal (the criteria have the same level of importance). In Scenario 2 it shows that the more relevant sub-criteria are $\mathrm{C} 2$ and C3. In Scenario 3 the sub-criteria that dominate in the analysis are $\mathrm{C} 3$ followed by $\mathrm{C} 2$ and $\mathrm{C} 4$. These levels of importance or preference affect the final result.

Table III. - Weights for each sub-criteria

\begin{tabular}{|c|c|c|c|c|}
\hline \multicolumn{2}{|c|}{ SUB-CRITERIA } & $\begin{array}{c}\text { SCENARIO } \\
1\end{array}$ & $\overline{\text { SCENARIO } 2}$ & $\begin{array}{c}\text { SCENARIO } \\
3\end{array}$ \\
\hline \multirow[t]{3}{*}{ Technical } & $\mathrm{C} 1$ & 0.10 & 0.11 & 0.08 \\
\hline & $\mathrm{C} 2$ & 0.10 & 0.13 & 0.17 \\
\hline & $\mathrm{C} 3$ & 0.10 & 0.12 & 0.35 \\
\hline \multirow[t]{2}{*}{ Economic } & $\mathrm{C} 4$ & 0.10 & 0.11 & 0.17 \\
\hline & C5 & 0.10 & 0.11 & 0.03 \\
\hline \multirow[t]{3}{*}{ Environmental } & C6 & 0.10 & 0.09 & 0.03 \\
\hline & C7 & 0.10 & 0.09 & 0.03 \\
\hline & C8 & 0.10 & 0.08 & 0.06 \\
\hline \multirow[t]{2}{*}{ Social } & C9 & 0.10 & 0.09 & 0.03 \\
\hline & $\mathrm{C} 10$ & 0.10 & 0.08 & 0.05 \\
\hline
\end{tabular}

\section{Application software Visual Promethee}

Visual PROMETHEE is a software that is based on PROMETHEE methodology. Evaluates different alternatives that have differences in their characteristics. 
points are identified and defined conflict which alternative is the best solution [27].

\section{Results}

PROMETHEE method performs a pairwise comparison of alternatives, integrating jointly all sets of criteria. As a result, the net flow delivered for each alternative. With net flows shown in Table IV for each alternative, a partial classification could be done for different scenarios. Alternatives more net flow will be considered more appropriate than the others, while they have a negative net flow will not be considered as a viable solution.

With the surveys performed, the main results shows in Scenario 1 that the best alternative is the location of Turi, followed by Yanuncay, then Baños and finally El Vecino. In Scenario 2, Turi remains as best option followed by Yanuncay, then El Vecino, finally Baños. The similarity of this results is due to the preference level imposed by the weights.

Weights of criteria aspects indicates that the main relevant sub criterion in Scenario 3 are: the power density, the height and geometry of buildings (turbulence) and finally, savings o importation of power achieved. Thus, the Yanuncay alternative is considered the best solution. Based on Table I, the buildings allowed height is considered for this sector. By having taller buildings, the wind speed is affected. This leads to greater power generation and in turn a higher profit. Yanuncay, followed by Turi, El Vecino and finally Baños. In Table IV, it shows the complete classification by PROMETHEE II.

Table IV. - Net flows for every alternative

\begin{tabular}{|c|c|c|c|c|}
\hline SOLUTION & ALTERNATIVE & $\begin{array}{c}\text { SCENARIO } \\
1\end{array}$ & $\begin{array}{c}\text { SCENARIO } \\
2\end{array}$ & $\begin{array}{c}\text { SCENARIO } \\
3\end{array}$ \\
\hline 1 & Turi & 0,2 & 0,2475 & 0,1275 \\
\hline 2 & Yanuncay & $-0,0333$ & $-0,0264$ & 0,2684 \\
\hline 3 & Baños & $-0,0667$ & $-0,1155$ & 0,1951 \\
\hline 4 & El Vecino & $-0,1$ & $-0,1056$ & 0,0759 \\
\hline
\end{tabular}

The PROMETHEE II classification allows full comparison of alternatives in terms of weights and preferences established by decision makers.

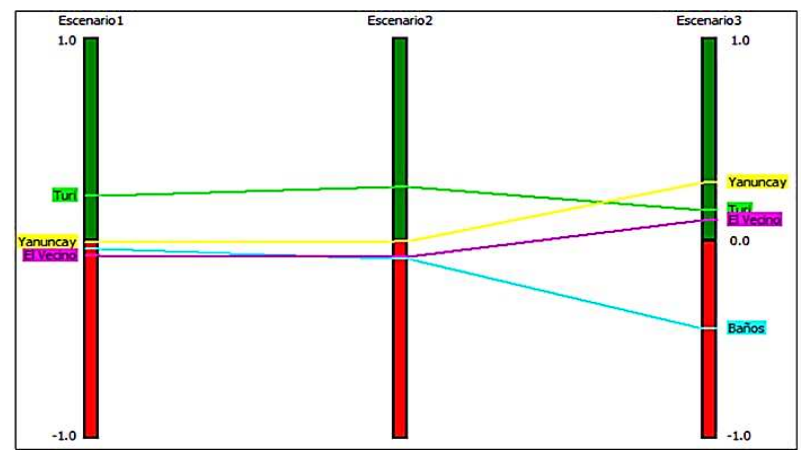

Fig.5. Complete Classification PROMETHEE II

Alternatives are located hierarchically based on their net flux a rating scale from -1 to 1 . As can be seen in Fig. 5,
Turi is positioned as the only alternative in Scenarios 1 and 2. While the Stage 3 has giving higher preference to the technical and economic criteria, then Yanuncay is positioned as best alternative followed by Turi and El Vecino.

Turi is an area on urbanisation process, maintaining some rural characteristics. The density of buildings is low and the turbulence intensity is less than in Yanuncay. Besides larger empty area is observed that allows to place wind turbines. It is located at a higher altitude place, so Yanuncay has a higher power density, which would provide a greater economic benefit.

Environmental impact concerns are higher when comparing Turi against Yanuncay, considering that this second option is already an urban area, but Turi is a scenically exposed site from the city. Yanuncay has higher population density and lower building presence so wildlife taks an important role. In concordance with these aspects, the Turi alternative is selected as the best solution especially for the theoretical wind potential. But with restrains because it implies important affectations with respect to the other criteria, specially quality ones.

\section{Discussion}

The wind potential of the urban area of Cuenca city has been discussed in reference with other urban environments [6]. But, there were no studies evaluating the benefit and restraint from the use of this potential.

The figure out the best option to incorporate accordingly a technology in a site, it is possible to apply decision making methodologies, considering various criteria [28]. In this study, ten sub-criteria including technical, economic, social and environmental has been taken account, and in three different scenarios are evaluated. Social aspects play an important role in the planning stage when implementing electrical projects are going to be analysed and these, in turn must have the same importance as the other criteria for comparison [28]. Thus, in Scenarios 1 and 2 proposed, the social aspects present a similar level to the other sub-importance.

The analysis results that in the sector Turi is best suited for implementing wind turbines. This is proportional to the altitude as discussed previously [8], with a higher wind speed and less turbulence, thereby potentially with a greater benefit. In a literature review [29], it has been affirmed that open areas that have good wind conditions and with suitable mounting heights are best suitable for micro generation. This indicates that when the wind comes in contact with buildings it creates turbulence zones where the wind potential cannot be exploited. Then El Vecino neighbourhood being an area with a high building density lose preponderance.

\section{Conclusion}

PROMETHEE method is an alternative for the selection of the best option for the exploitation of wind resources, 
this study has implemented it in the city of Cuenca. It was possible to integrate different criteria, as well as different rating scales for alternatives. The Turi sector is considered as the optimal solution for micro generation according to this methodology applied. This location meets the necessary conditions under the evaluation criteria. It shows both technical and geographical features that make the wind potential suitable for power production, although it is a sensitive area from landscape perspective and should be carefully analysed and visual aspects of mitigation must be considered. By having a greater use of wind, greater economic benefits are achieved. Besides environmental impacts must be analysed in depth to reduce them through specific studies.

\section{References}

[1] L. Battisti, E. Benini, A. Brighenti, S. Dell'Anna, M. Raciti Castelli, Small wind turbine effectiveness in the urban environment, Renew. Energy. 129 (2018) 102-113.

[2] B. Grieser, Y. Sunak, R. Madlener, Economics of small wind turbines in urban settings: An empirical investigation for Germany, Renew. Energy. 78 (2015) 334-350.

[3] P. Irwin, R. Denoon, D. Scott, Wind Tunnel Testing of HighRise Buildings: An output of the CTBUH Wind Engineering Working Group, Counc. Tall Build. Urban Habitat. (2013). https://store.ctbuh.org/PDF_Previews/Books/201 3_WindTunnelGuide_Preview.pdf.

[4] S.L. Walker, Building mounted wind turbines and their suitability for the urban scale-A review of methods of estimating urban wind resource, Energy Build. 43 (2011) 1852-1862. doi:10.1016/j.enbuild.2011.03.032.

[5] F. Toja, A. Colmenar, and M. Castro, "Urban wind energy exploitation systems: Behaviour under multidirectional flow conditions - Oppor- tunities and challenges," Renewable and Sustainable Energy Reviews, vol. 24, pp. 364-378, 2013.

[6] A. S. Yang, Y.M. Su, C. Y. Wen, Y.H. Juan, W. S. Wang, and C. H. Cheng, "Estimation of wind power generation in dense urban area," Applied Energy, vol. 171, pp. 213-230, 2016. [Online]. http://dx.doi.org/10.1016/j.apenergy.2016.03.007

[7] L. Battisti, E. Benini, A. Brighenti, S. Dell'Anna, and M. Raciti Castelli, "Small wind turbine effectiveness in the urban environment," Renewable Energy, vol. 129, pp. 102$113,2018$.

[8] T. F. Ishugah, Y. Li, R. Z. Wang, and J. K. Kiplagat, "Advances in wind energy resource exploitation in urban environment: A review," Renewable and Sustainable Energy Reviews, vol. 37, pp. 613-626, 2014.

[9] G. Fernández and M. d. C. Escribano, "La Ayuda a la Decisión Multicriterio: orígenes, evolución y situación actual," pp. 1-19, 2011.

[10] G. Munda, "Teoría de evaluación multicroterio: una breve perspectiva general," pp. 1-30, 1997.

[11] J. F. Pacheco and E. Contreras, Manual para la evaluación multicriterio para programas y proyectos, 2008.

[12] J. Mayor, "Propuesta de un modelo de decisión multicriterio para la adjudicación de contratos de proyectos de infraestructura de iniciativa pública en Colombia," p. 99, 2015.

[13] E. Løken, "Use of multicriteria decision analysis methods for energy planning problems," Renewable and Sustainable Energy Reviews, vol. 11, no. 7, pp. 1584-1595, 2007.

[14] M. Behzadian, R. B. Kazemzadeh, A. Albadvi, and M. Aghdasi, "PROMETHEE: A comprehensive literature review on methodologies and applications," European Journal of Operational Research, vol. 200, no. 1, pp. 198-215, 2010. [Online]. Available: http://dx.doi.org/10.1016/j.ejor.2009.01.021

[15] S. D. Pohekar and M. Ramachandran, "Application of multi-criteria decision making to sustainable energy planning - A review," Renewable and Sustainable Energy Reviews, vol. 8, no. 4, pp. 365-381, 2004.

[16] M. Goumas and V. Lygerou, "An Extension of the PROMETHEE method for decision making in fuzzy environment: Ranking of alter- native energy exploitation projects," European Journal of Operational Research, vol. 123, no. 3, pp. 606-613, 2000.

[17] J. Constante and M. M. Cajas, "Métodos para homogenizar y rellenar datos de viento de la torre meteorológica del Parque Eólico Villonaco en LojaEcuador Methods to homogenize and fill the wind data from the mete..." no. June 2016, 2015.

[18] International Electrotechnical Commission - Provided by IHS under license with IEC, "IEC 61400-12-1 International Standard - Wind Turbines," vol. 2005, 2005.

[19] A. H. Lee, H. H. Chen, and H. Y. Kang, "Multi-criteria decision making on strategic selection of wind farms," Renewable Energy, vol. 34, no. 1, pp. 120-126, 2009.

[20] W. Yunna and S. Geng, "Multi-criteria decision making on selection of solar-wind hybrid power station location: A case of China," Energy Conversion and Management, vol. 81, pp. 527-533, 2014. [Online]. Available: http://dx.doi.org/10.1016/j.enconman.2014.02.056

[21] Agencia de Regulación y Control de Electricidad, "Pliego tarifario para las empresas eléctricas de distribución. Servicio público de energía eléctrica. Periodo: enero - diciembre 2018," vol. 18, pp. 1-18, 2018. [Online]. Available: http://www.regulacionelectrica.gob.ec/wpcontent/uploads/downloads/2018/01/2018-01-11-Pliego-yCargos-Tarifarios-del-SPEE-20182.pdf

[22] J. J. Watson and M. D. Hudson, "Regional Scale wind farm and solar farm suitability assessment using GISassisted multi-criteria evaluation," Landscape and Urban Planning, vol. 138, pp. 20-31, 2015. [Online]. Available: http://dx.doi.org/10.1016/j.landurbplan.2015.02.001

[23] S. Değirmenci, F. Bingöl, and S. Sofuoglu, "MCDM analysis of wind energy in Turkey: decision making based on environmental impact," Environmental Science and Pollution Research, vol. 2016, no. Twea 2016, 2018.

[24] A. Barragán, P. Arias, and J. Terrados, "Renewable Energy Generation Technologies on Urban Scale," Renewable Energy and Power Quality . . . , vol. 1, no. $15,2017 . \quad$ [Online]. Available: http://www.icrepq.com/icrepq17/432-17-barragan.pdf

[25] S. Briefs and I. N. Water, Noorul Hassan Zardari Kamal Ahmed Sharif Moniruzzaman Shirazi Zulkifli Bin Yusop, 2015.

[26] D. Diakoulaki, G. Mavrotas, and L. Papayannakis, "D E T E R M I N I N G OBJECTIVE WEIGHTS IN M U L T I P L E CRITERIA PROBLEMS : THE CRITIC M E T H O D," vol. 22, no. 7, pp. 763-770, 1995.

[27] B. Mareschal, "Visual PROMETHEE manual," pp. 1-192, 2013.

[28] A. Kumar, B. Sah, A. R. Singh, Y. Deng, X. He, P. Kumar, and R. C. Bansal, "A review of multi criteria decision making (MCDM) towards sustainable renewable energy development," Renewable and Sustainable Energy Reviews, vol. 69, no. June 2016, pp. 596-609, 2017. [Online]. Available: http://dx.doi.org/10.1016/j.rser.2016.11.191

[29] S. R. Allen, G. P. Hammond, and M. C. McManus, "Prospects for and barriers to domestic micro-generation: A United Kingdom perspective," Applied Energy, vol. 85, no. 6 , pp. 528-544, 2008.

[30] Cuenca, G. M. (2016). Atlas Cartográfco del Plan de Desarrollo y Ordenamiento Territorial, 105: http://www.cuenca.gob.ec/?q=page_planordenamiento 
